\title{
An investigation on the renal portal system in long-legged buzzard (Buteo rufinus)
}

\author{
Sedef SELVILER SIZER ${ }^{1, a, ®}$, Murat KABAK ${ }^{2, b}$, Burcu ONUK ${ }^{2, c}$ \\ ${ }^{1}$ Ondokuz Mayıs University, Graduate School of Health Sciences, Samsun; ${ }^{2}$ Ondokuz Mayıs University, Faculty of Veterinary \\ Medicine, Department of Anatomy, Samsun, Turkey. \\ aORCID:0000-0002-1990-4507; ' ORCID: 0000-0003-4255-1372; ' ORCID: 0000-0001-8617-3188. \\ Corresponding author: sedef.selviler@omu.edu.tr \\ Received date: 21.01.2020 - Accepted date: 15.06.2020
}

\begin{abstract}
This study was carried out for the morphological examination of renal portal system in the long-legged buzzard. A total of nine adult long-legged buzzards were used in the study. The latex procedure was performed for the macroanatomic detection of the vessels forming the renal portal system. Dissections were performed under the stereomicroscope and later photographs were taken. The renal portal system vessels formed by the cranial renal portal vein and caudal renal portal vein in the long-legged buzzard. Afferent renal branches were separated from these vessels and efferent renal branches were observed to join renal veins. The anastomosis of the left cranial renal portal vein and right cranial renal portal vein was not observed at the cranial side, besides the presence of interiliac anastomosis was determined between the right internal iliac vein and left internal iliac vein at the caudal side. The findings of the renal portal system of long-legged buzzard (Buteo rufinus) were generally similar to those noted in other birds.

Keywords: Anatomy, long-legged buzzard, renal portal system.
\end{abstract}

\section{Kızıl şahin'de (Buteo rufinus) renal portal sistem üzerine bir araştırma}

Özet: Bu çalışma kızıl şahinde renal portal sistemin morfolojik olarak incelenmesi amacıyla yapılmıştır. Çalışmada toplam 9 adet yetişkin kızıl şahin kullanıldı. Renal portal sistemi oluşturan damarların makroanatomik tespiti için latex uygulandı. Diseksiyonlar steromikroskop altında yapıldı ve daha sonra fotoğrafları çekildi. Kızıl şahin'de renal portal sistem damarları, vena portalis renalis cranialis ve vena portalis renalis caudalis'ten oluşmaktaydı. Bu damarlardan afferent renal dalların ayrıldığı ve efferent renal dalların vena renalis'e katıldığı gözlendi. Cranial tarafta vena portalis renalis cranialis dexter ve vena portalis renalis cranialis sinister arasında anastomoz görülmezken, caudal tarafta, vena iliaca interna dexter ve vena iliaca interna sinister arasında (interiliac anastomosis) anastomozun varlığı belirlendi. Kızıl şahin (Buteo rufinus) renal portal sisteminin bulguları genel olarak diğer kuşlarda belirtilenlerle benzer bulundu.

Anahtar sözcükler: Anatomi, kızıl şahin, renal portal sistem.

\section{Introduction}

The kidneys are responsible for providing body homeostasis by filtering the waste products as a result of metabolism $(13,18)$. They generally weigh about $1 \%$ of body weight and their color changes according to the amount of blood they contain $(1,13)$. The kidneys of birds which are different from the mammals consist of three lobes symmetrically lying on the renal fossa of the synsacrum $(6,10,12,14,16)$. Another difference is that, renal portal system in birds consists of a lot of vessels and carries venous blood to the proximal tubule $(2,8,10,12$, 13). This system plays an important role in nourishing the nephrons $(3,10)$. Thus, venous blood is transported to the tubules responsible for the creation of the urine $(3,13)$.
Kidneys receive afferent blood that comes from high pressure renal arteries and from low pressure renal portal system $(8,9)$. Cranial and caudal renal portal veins located in the renal portal system are branches of external iliac vein. While cranial renal portal vein receives venous blood only from the hind limb, the caudal renal portal vein receives venous blood from the hind limb, pelvis, coccyx and caudal mesenteric vein (2). The cranial renal portal vein supplies venous blood to the cranial lobe. Caudal renal portal vein supplies venous blood to the middle and caudal lobes (2). The caudal mesenteric vein is particularly important due to providing a direct connection between the renal portal system and the hepatic portal system $(5,12,13)$. The renal portal valve located in the 
lumen of the common iliac vein provides the blood flow in the renal portal system. When this valve is open, the portal blood bypasses the kidney and goes to the caudal vena cava $(2,9)$. When the valve is closed, the blood flows into the renal parenchyma $(5,13)$.

Although the knowledge about renal portal system in different species is presented, no literature information about the subject has been encountered in long-legged buzzard. Therefore, this study aimed to determine the anatomical structure of renal portal system in long-legged buzzard.

\section{Material and Methods}

In this study, 9 adult long-legged buzzards (Buteo rufinus), weighing between 900-1520 gr, were examined. The material of our study were collected from long-legged buzzards that were brought to the faculty clinic due to various injuries and died during treatment. The vessels were washed with $0.9 \%$ saline solution. Via a cannula, latex colored with red and blue dyes were injected into descending aorta and caudal vena cava, respectively. The materials were left at room temperature $24 \mathrm{~h}$ and then fixated with $10 \%$ formalin. Veins that belong to the renal portal system were determined by dissection under the stereomicroscope (Model SZ6, Olympus Corporation, Japan). The photographs were taken with the digital camera (Model C-5060, Olympus Corporation, Japan).

\section{Results}

In the long-legged buzzard, the kidneys located in renal fossa that extend from the caudal of the lungs to the synsacrum were determined to be composed of three lobes that include cranial, middle and caudal (Figure 1). The length-width of the cranial $(17.82 \pm 1.79 \mathrm{~mm}-11.75 \pm 1.5$ $\mathrm{mm})$, middle $(9.63 \pm 2.16 \mathrm{~mm}-5.13 \pm 0.70 \mathrm{~mm})$ and caudal
$(12.13 \pm 1.93 \mathrm{~mm}-9.72 \pm 1.84 \mathrm{~mm})$ lobes of the right side and the length- width of the cranial $(17.44 \pm 2.33 \mathrm{~mm}$ $12.51 \pm 1.4 \mathrm{~mm})$, middle $(8.85 \pm 1.47 \mathrm{~mm}-6.43 \pm 3.07 \mathrm{~mm})$ and caudal $(12.24 \pm 1.39 \mathrm{~mm}-8.75 \pm 2.17 \mathrm{~mm})$ lobes of the left side were measured.

The renal portal system vessels were formed by cranial and caudal renal portal veins in the long-legged buzzard. The cranial and caudal renal portal veins were branches of right and left external iliac veins (Figure 2). The caudal renal portal vein was first removed from the external iliac vein. After average $1.67 \mathrm{~mm}$, cranial renal portal vein was separated from external iliac vein. Immediately after this separation, the external iliac vein formed anastomosis with the caudal renal vein. A narrowing was detected in this area during latex applications. This narrowing was defined as renal portal valve (Figure 2). The external iliac vein continued as the common iliac vein after the renal portal valve and then opened to the caudal vena cava. Afferent renal branches were separated from both cranial renal portal vein and caudal renal portal vein and spread into the kidneys (Figure 2). While the afferent branches of cranial renal portal vein entered only to cranial kidney lobe, the afferent branches of caudal renal portal vein entered to both middle and caudal kidney lobes. Efferent branches were observed to join renal veins. The caudal renal vein was continued side by side with the ureter (Figure 3 ). It was determined that the ischiadic vein joined the caudal renal portal vein at the cranial level of the caudal renal lobes (Figure 3). And then, it was observed that this vessel, which has gone through the caudal lobe, was anastomosed with the internal iliac vein at the caudal level of the renal lobe. Right and left internal iliac veins joined at caudal level of the caudal lobe and formed an interiliac anastomosis (Figure 4). It was observed that the caudal mesenteric vein was opened to this anastomosis region (Figure 4).

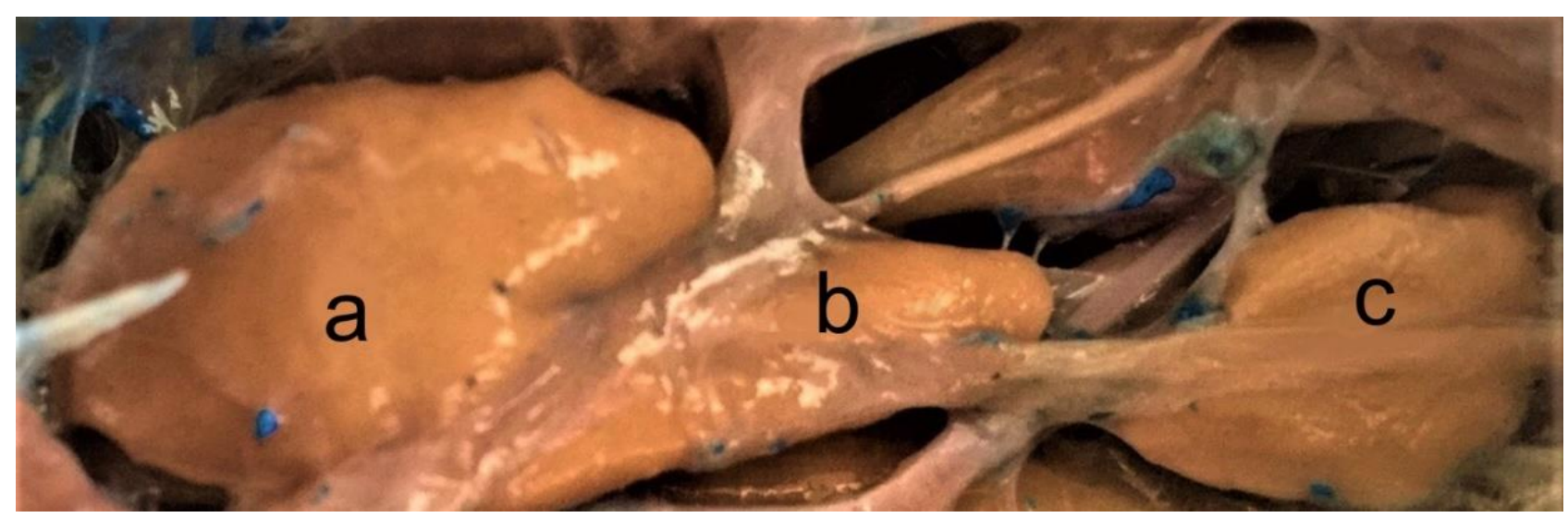

Figure 1. Ventral view of the kidneys. a: left cranial lobe; b: left middle lobe; c: left caudal lobe. 


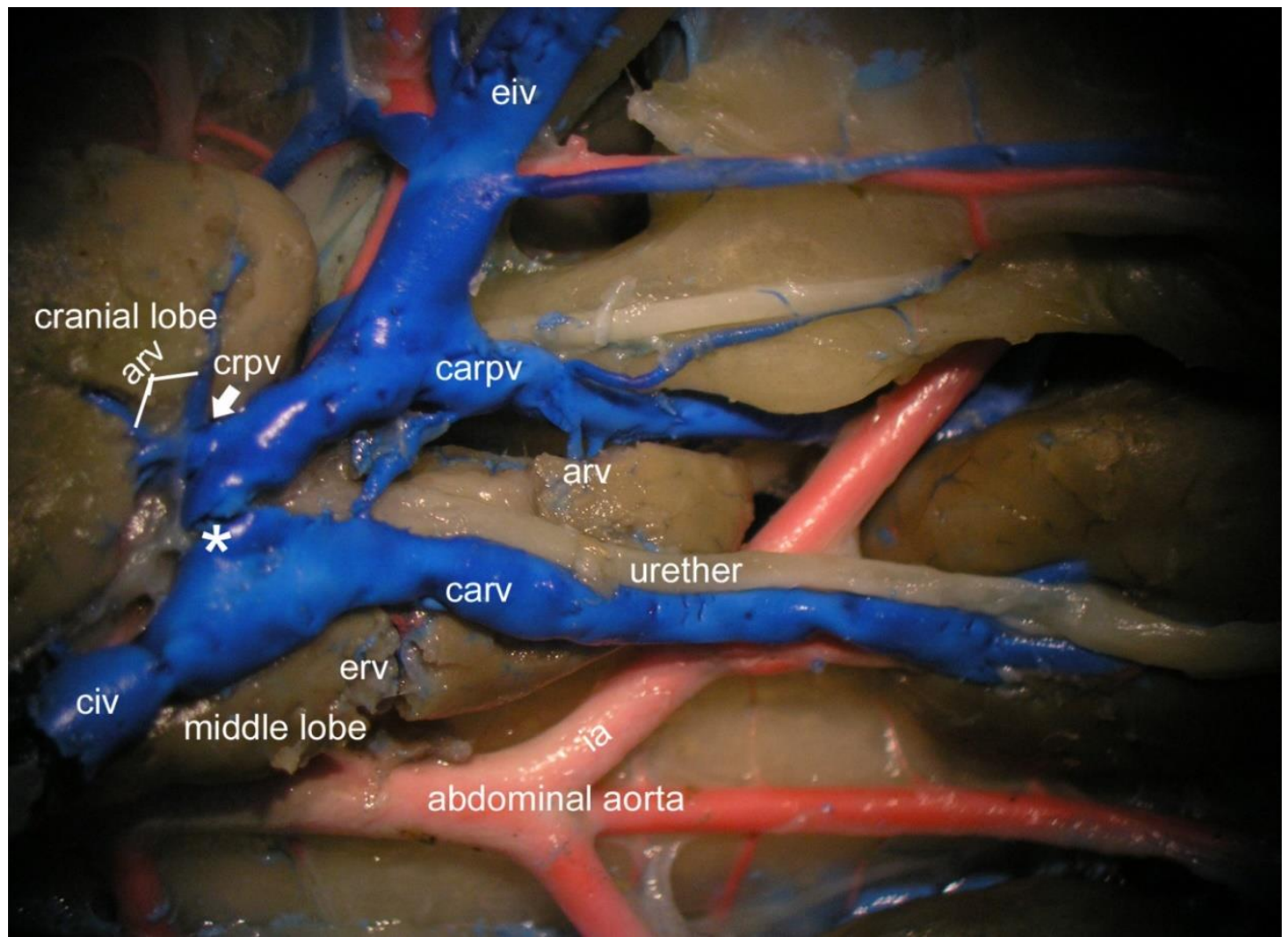

Figure 2. A view of the vessels associated with the kidneys. eiv: external iliac vein; civ: common iliac vein; crpv: cranial renal portal vein; carpv: caudal renal portal vein; carv: caudal renal vein; erv: efferent renal vein; arv: afferent renal vein; ia: ischiadic artery; *: renal portal valve.

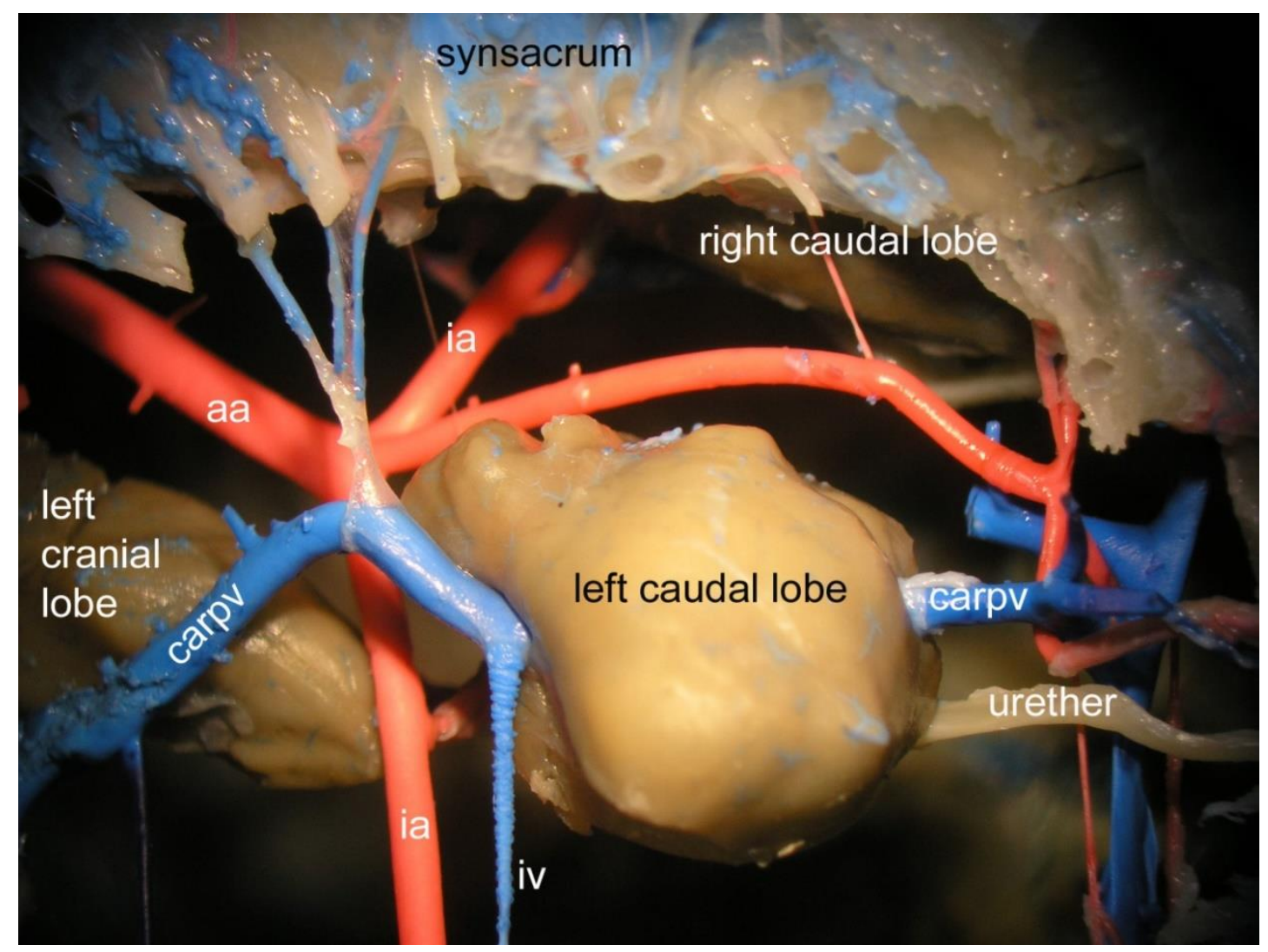

Figure 3. Lateral view of the vessels associated with the kidneys. carpv: caudal renal portal vein; aa: abdominal aorta; ia: ischiadic artery; iv: ischiadic vein. 


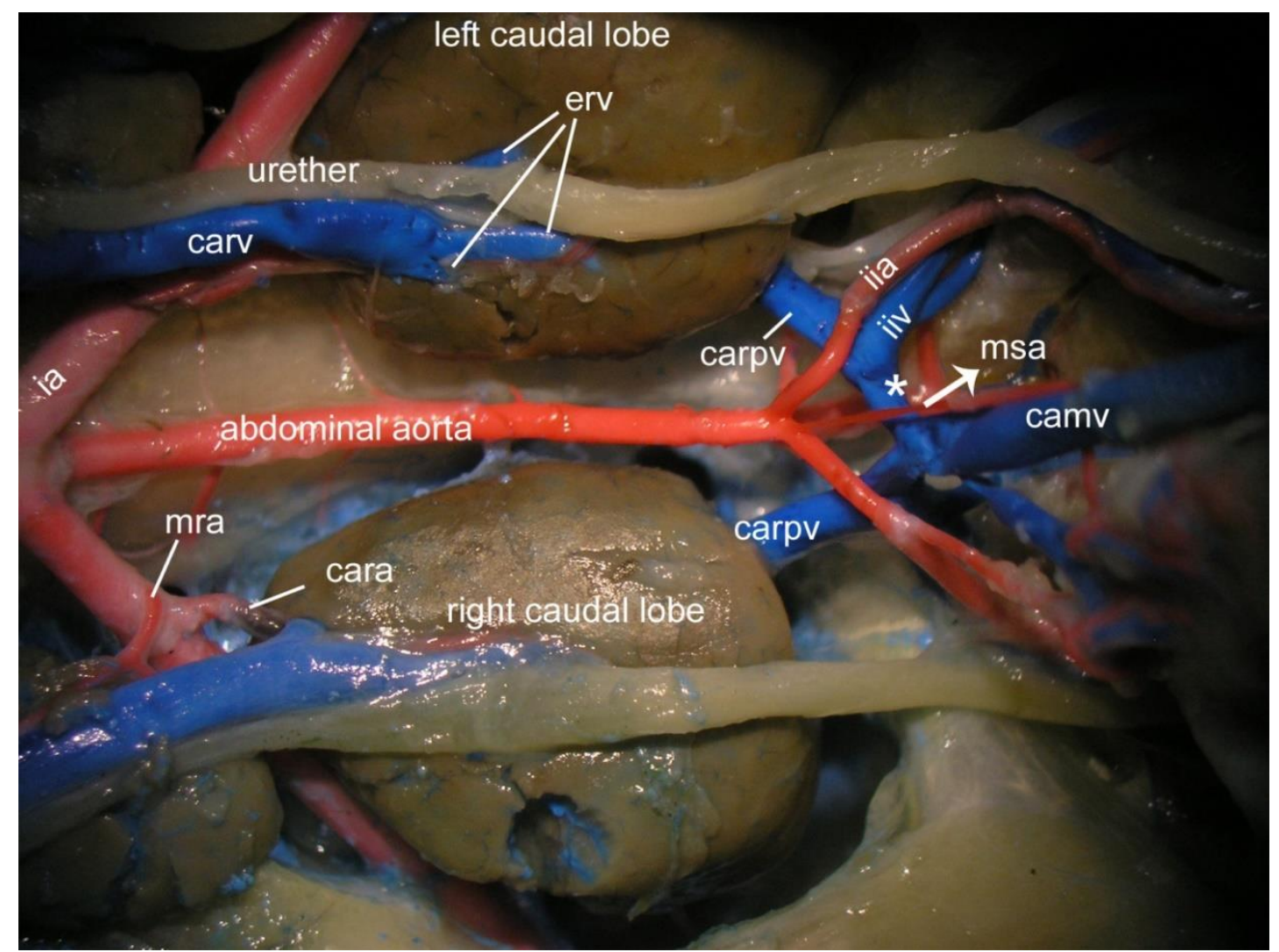

Figure 4. Ventral view of the vessels associated with the kidneys. carv: caudal renal vein; erv: efferent renal vein; carpv: caudal renal portal vein; camv: caudal mesenteric vein; ia: ischiadic artery; mra: middle renal artery; cara: caudal renal artery; iia: internal iliac artery; iiv: internal iliac vein; msa: middle sacral artery; *: interiliac anastomosis.

\section{Discussion and Conclusion}

Although the number of kidney lobes was reported as two lobes in hornbill (11), in many species, such as coot bird (7), domestic fowl (15), emu (14), harrier (1), mallard duck (1), and golden eagle (4), it has been reported that it consists of three lobes. In our study, the kidneys of the long-legged buzzard were composed of three lobes were similar to many other species. It was mentioned that kidneys were located in the renal fossa, which extends from the caudal of lungs to the synsacrum, in some species such as rock dove (16), flamingos (17), coot bird (7), owl (16) and harrier (1). This localization of the kidneys was compatible with the above-mentioned literatures.

The renal portal system in avian, which is different from mammals, allows the excretion of uric acid by tubular secretion $(10,13,17)$. The vessels in this system may differ between species $(5,8,12)$. The cranial and caudal renal portal veins were separated from the external iliac vein on both the right and left sides in pigeon (5) and domestic fowl (3). There were differences at the right and left sides in cape griffon vulture (12). At left side, the cranial renal portal vein, the caudal renal portal vein and caudal renal vein arose from the common iliac vein. At right side, the caudal renal vein and the caudal renal portal vein were firstly joined and then entered to the common iliac vein. In our study, cranial and caudal renal portal veins and caudal renal veins were similar to pigeon and domestic fowl when looking at the exit points. There was no differences at the right and left sides. It has been reported that, while afferent renal branches are separated from renal portal veins, efferent renal branches join the renal veins $(12,13)$. In the long-legged buzzard, it was found similar to those mentioned in Havenga (12) and King and McLelland (13). King and McLelland (13) stated that the presence of a venous ring occurs by anastomosis of the left and right cranial renal portal veins in the cranial side. In pigeon (5), there is no mention of such a venous ring. In this study, the venous ring was not observed, so it was similar to that mentioned in the pigeon. It has been reported that the renal portal valve provides blood flow into the renal portal system $(2,9,13)$. There are differences in the literature about the localization of the renal portal valve. It has been stated that this valve is located in the lumen of the common iliac vein by Havenga (12) in cape griffon vulture and Canny (9) in avian. In our study, same valve found in lumen before forming anastomosis between the external iliac and renal veins as stated in domestic fowl by Akester (2).

The caudal renal portal vein which is separated from the external iliac vein forms anastomosis with the internal 
iliac vein on both sides and in caudal side. Then, both internal iliac veins merge to form the interiliac anastomosis. This interiliac anastomosis is involved with the caudal mesenteric vein (cocygeomesenteric) that has a direct connection between the renal portal system and the hepatic portal system $(5,12)$. The course and connections of the caudal renal portal vein mentioned above were compatible with our study.

With this study, for the first time, the morphological structure of the renal portal system in the long-legged buzzard was examined in details. The renal portal system consisted of cranial and caudal renal portal veins. The results of this study will contribute to the anatomy literature and will help researchers to work on the subject.

\section{Acknowledgements}

A part of this study is presented as oral presentation at the $" 5^{\text {th }}$ International Group Congress $\& 8^{\text {th }}$ International Scientific Meeting Vet-Istanbul Days of Veterinary Medicine" on the 23-27 $7^{\text {th }}$ September 2018.

\section{Financial Support}

This research received no grant from any funding agency/sector.

\section{Ethical Statement}

This study does not present any ethical concerns.

\section{Conflict of Interest}

The authors declared that there is no conflict of interest.

\section{References}

1. Abood DA, Ali FR, Azhar SK, et al (2014): Comparative anatomical and histological features of the kidney in harrier (Circus aueroginosus), chicken (Gallus domesticus) and mallard duck (Anas platyrhynchos). The Iraqi J Vet Med, 38, 107-113.

2. Akester AR (1964): Radiographic studies of the renal portal system in the domestic fowl (Gallus domesticus). J Anat, 98, 365-376.
3. Akester AR (1967): Renal portal shunts in the kidney of the domestic fowl. J Anat, 101, 569-594.

4. Al-Agele RA (2012): Study the anatomical descriptions and histological observations of the kidney in golden eagles (Aquila Chrysaetos). The Iraqi J Vet Med, 36, 145-152.

5. Al-Ajeely RA, Mohammed FS (2012): Morphohistological study on the development of kidney and ureter in hatching and adulthood racing pigeon (Columba livia domestica). Int J Sci Nature, 3, 665-677.

6. Bahadır A, Yıldız H (2015): Veteriner Anatomi. Ezgi Kitabevi, Bursa.

7. Batah AL (2012): Morphological and histological study for the kidneys of coot bird (Fulica atra). Bas J Vet Res, 11, 128-136.

8. Blackburn R, Prashad D (1990): The avian renal portal system: A model for studying nephrotoxicity of xenobiotics. Toxicol Lett, 53, 219-221.

9. Canny C (1998): Gross anatomy and imaging of the avian and reptilian urinary system. Semin Avian Exot Pet Med, 7, 72-80.

10. Dursun N (2007): Evcil kuşların anatomisi. Medisan Yayın Serisi, Ankara.

11. Feinstein B (1962): Additional cases of bilobated kidneys in the hornbills. The Auk, 79, 709-711.

12. Havenga LN (2015): A morphological study of the kidney and renal portal system of the Cape griffon vulture (Gyps coprotheres). MSc dissertation. University of Pretoria, South Africa.

13. King AS, McLelland J (1984): Birds, Their Structure and Function. Bailliere Tindall Ltd, London.

14. Michalek K, Szczerbinska D, Grabowska M, et al (2016): Anatomical and morphological study of the kidneys of the breeding eтu (Dromaius novaehollandiae). Turk J Zool, 40, 314-319.

15. Morild I, Bohle A, Christensen JA (1985): Structure of the avian kidney. Anat Rec, 212, 33-40.

16. Nabipour A, Alishahi E, Asadian M (2009): Some histological and physiological features of avian kidney. $\mathbf{J}$ Appl Anim Res, 36, 195-198.

17. Reshag AF, Abood DA, Dawood MS (2016): Anatomical and histological study of the kidneys and salt glands in great flamingos (Phoenicopterus roseus). The Iraqi J Vet Med, 40, 140-146.

18. Simon E (1982): The osmoregulatory system of birds with salt glands. Comp Biochem Physiol, 71, 547-556. 